\title{
No evidence that vaccines cause insulin dependent diabetes mellitus
}

\author{
Tom Jefferson, Vittorio Demicheli
}

Histological and serological findings in insulin dependent diabetes mellitus (IDDM) are consistent with autoimmune causes and recent work suggests polygenic inheritance. The incidence in developed countries seems to be increasing, ${ }^{1}$ although it is unclear whether this

Table 1 Incidence of insulin dependent diabetes mellitus in children under 15 years of age from registers of selected worldwide countries. Incidence estimates are derived from national or subnational registers. After Karvonen et al ${ }^{l}$

\begin{tabular}{|c|c|c|}
\hline Region Country & Study period & $\begin{array}{l}\text { Incidence rates per } \\
100000\end{array}$ \\
\hline \multicolumn{3}{|l|}{ Africa } \\
\hline Algeria & $1980-89$ & 8.1 \\
\hline Tanzania & $1982-91$ & 0.8 \\
\hline Sudan & $1987-90$ & 6.4 \\
\hline \multicolumn{3}{|l|}{ North America } \\
\hline Canada & $1971-85$ & 9.8 \\
\hline Cuba & $1978-80$ & 2.7 \\
\hline Mexico & $1984-86$ & 0.6 \\
\hline Puerto Rico & $1985-89$ & 10.0 \\
\hline \multicolumn{3}{|l|}{ United States } \\
\hline North Dakota & $1980-86$ & 18.9 \\
\hline Wisconsin & $1970-79$ & 18.2 \\
\hline Allegheny County & $1970-85$ & 17.3 \\
\hline Rochester & $1965-79$ & 17.1 \\
\hline Colorado & $1978-88$ & 15.5 \\
\hline San Diego & $1978-81$ & 9.4 \\
\hline \multicolumn{3}{|l|}{ South America } \\
\hline Brazil & $1987-91$ & 7.6 \\
\hline Chile & $1990-91$ & 2.5 \\
\hline \multicolumn{3}{|l|}{ Asia } \\
\hline Israel & $1975-80$ & 4.5 \\
\hline Japan & $1974-86$ & 1.7 \\
\hline Kuwait & $1980-81$ & 4.0 \\
\hline Republic of Korea & $1985-86$ & 0.6 \\
\hline Russia & $1983-89$ & 4.6 \\
\hline \multicolumn{3}{|l|}{ Oceania } \\
\hline \multirow{2}{*}{\multicolumn{3}{|c|}{ Europe }} \\
\hline & & \\
\hline Denmark & $1989-90$ & 21.5 \\
\hline Finland & $1987-89$ & 35.3 \\
\hline France & $1989-90$ & 7.8 \\
\hline Germany & $1960-89$ & 7.4 \\
\hline Greece & $1989-90$ & 9.3 \\
\hline Italy & $1989-90$ & 6.8 \\
\hline Latvia & $1983-88$ & 6.5 \\
\hline Malta & $1980-87$ & 13.6 \\
\hline Netherlands & $1989-90$ & 11.0 \\
\hline Norway & $1989-90$ & 20.8 \\
\hline Poland & $1989-90$ & 5.5 \\
\hline Portugal & $1989-90$ & 7.5 \\
\hline Romania & $1989-90$ & 5.1 \\
\hline Slovenia & $1988-90$ & 6.5 \\
\hline Spain & $1985-88$ & 10.9 \\
\hline Sweden & $1978-87$ & 24.4 \\
\hline United Kingdom & 1988 & 13.5 \\
\hline
\end{tabular}

Table 2 Template grid used to select studies by topic

Cochrane Vaccines

Field, Army Medical

Directorate, Ministry

of Defence, Keogh

Barracks, Ash Vale, Hants GU12 5RR,

United Kingdom

Correspondence to: Dr Jefferson.

Accepted for publication 30 March 1998

IDDM

Other autoimmune disease

Occurence of disease

Natural history

Risk factors

vaccination

infections

genetic factors

socioeconomic factors

environmental factors

other

Autoimmunity

Mechanisms of immunity

$\mathrm{T}$ cell vaccination finding is real or artefactual. Given the age of the victims of IDDM and marked differences in incidence of the disease in children under $15^{1}$ (see table 1), international attention has began focusing on the nature of possible external stimuli in the genesis of IDDM. Among these, vaccination schedules have been also called into question as possible modulating factors. Classen and Classen have postulated a protective effect of exposure to immunogens if babies are vaccinated within 42 days from birth. ${ }^{2}$ It is known that genetic manipulation in animal models followed by early challenge with vaccine antigen can precipitate onset of

\section{Table 3 Checklist used to assess study relevance and} quality

1. Review : Immunisation and IDDM

2. Study identity

2.1 Study number:

2.2 First author:

2.3 Country:

2.4 Institution:

2.5 Sponsorship:

2.6 Vancouver (Journal. Year; volume: pages)

3. Issues covered by the study

IDDM

Other autoimmune disease

Occurrence of disease

Natural history

Risk factors

vaccination

infections

genetic factors

socioeconomic factors

environmental factors

other

Autoimmunity

Mechanisms of immunity

$\mathrm{T}$ cell vaccination

4. Study design

4.1 Type of study

descriptive

case study

analytical prospective

analytical retrospective

migrant study

experimental

review

comment

editorial

other

(only for experimental and analytical studies)

4.2 Comparisons:

4.3 Outcome measures:

4.4 Follow up duration (for each outcome measure)

5. Study population (only for experimental and analytical studies)

5.1 Human or animals:

5.2 Human population (general, at risk):

5.3 At risk group(s): 
IDDM. ${ }^{3}$ We report the results of a study aimed at assembling, examining, and summing up evidence of the possible link between vaccination schedules in humans and onset of IDDM. We carried out an exploratory review of current state of knowledge of human autoimmune disease, the causation of IDDM, and its possible links to human vaccination. By means of extensive searches of Medline, Embase, Biosis Previews, Current Biotechnology Abstracts, and Derwent Biotechnology Abstracts databases using ad hoc strategies we identified 95 possible studies. Selection was based on their coverage of at least one of the issues in the template grid in table 2 . We assessed the quality and content of each selected paper using the checklist at table 3 .

Of the 95 studies, we assessed 54 as possibly relevant of which only six directly tackled the study question. We interviewed eight researchers active in investigating trigger factors for IDDM. Evidence of a causal link in humans was sought by reviewing a sample of 12 large trials and two meta-analyses of paediatric vaccines.

We found that international analytical literature is insufficient and of limited coverage to shed light on the possible link between onset of IDDM and vaccination. There seem to be no reviews of the subject and no evidence in humans. The papers that explored the relation between vaccination and IDDM either did not find evidence of the causal link or found evidence against such a link. A Swedish childhood diabetes study found a significant decrease in odds ratio for measles vaccination $(\mathrm{OR}=0.69$; CI: $0.48,0.98)$ and no significant effect for tuberculosis, smallpox, tetanus, whooping cough, rubella and mumps vaccines. ${ }^{4}$ According to Hyoty ${ }^{5}$ the elimination of natural mumps by the MMR vaccination may have decreased the risk of developing IDDM in Finland and a recent epidemiological study found no difference in cumulative incidence rates of IDDM between two cohorts of children born before and after the exclusion of pertussis vaccine from the national vaccination schedule. ${ }^{6}$ The available experimental evidence does not allow any assessment of the links between time of vaccination and onset of IDDM as the 12 large randomised controlled trials and the two meta-analyses that we examined were not designed to capture long term possible adverse events such as IDDM. We conclude that at present there is no evidence of a link between IDDM and vaccination in humans.

Funding: the review was funded by the Department of Health of the United Kingdom.

The views expressed in the paper are those of the authors.

The authors would like to thank Drs Peter Greenaway, Brian Edwards, David Salisbury, Professor Peter Beverley, and Ms Helen Campbell for assistance.

Readers interested in the full details of methods used in the review should contact Professor Jefferson.

1 Karvonen M, Tuomilehto J, Libman I, et al. A review of the recent epidemiological data on worldwide incidence of Type 1 (insulin-dependent) diabetes mellitus. Diabetologia 1993;36:883-92.

2 Classen J B, Classen D C. Vaccines modulate IDDM. [Letter]. Diabetologia 1996;39:500-2.

3 Baxter AG, Cooke A. Peptide therapy for diabetes. Lancet 1994;343:1 168-9.

4 Blom L. The Swedish childhood diabetes study. Vaccinations and infections as risk determinants for diabetes in childhood. Diabetologia 1991;34:176-81.

5 Hyoty $\mathrm{H}$ and Childhood Diabetes in Finland Study Group. Decline of mumps antibodies in type 1 (insulin-dependent) diabetic children and a plateau in the rising incidence of type 1 diabetes after introduction of the mumps-measlesrubella vaccine in Finland. Diabetologia 1993;36:1303-8.

6 Hejbel H, Chen RT, Dahlquist G. The cumulative incidence of childhood onset insulin dependent diabetes mellitus (IDDM) is unaffected by pertussis immunization. Diabetes Care 1997;20:173-5. 